\title{
Improving maternal and reproductive health in Ethiopia
}

\author{
Yishak Lailulo, A Sathiya Susuman and Renette Blignaut
}

\begin{abstract}
This study aimed to examine the relationship between maternal health and good quality of life in an attempt to understand the years between 2005 and 2011. Data from the Ethiopia Demographic and Health Surveys 2005 and 2011 were used. Bivariate, Camer-V, chi-square and logistic regression analyses were used to determine the relative contribution of the predictor variables. The hypotheses tested in this study were that gender, wealth quintile, type of place of residence and region are highly significant with women's education and work status. Females' expected age (adjusted odds ratio $=$ AOR) for some school training has dropped in 2011 from 0.678 to 0.255 for the age group 25-34, but male expected age (AOR) for some school has increased in 2011 from 0.784 to 2.274. The age of the respondent, age at first cohabitation and socio-economic variables were positively associated with having visited health facilities in the last 12 months and being visited by a family planning worker.
\end{abstract}

\section{Introduction}

Women's empowerment is a development objective in and of itself as recognized in Millennium Development Goals (MDGs) three and five: to promote gender equality by empowering women and to improve maternal health, respectively. When women are educated, it reduces the number of children, decreases maternal mortality, and thus increases the health of their children (Agha, 2000; Bianchi, 2000).

Ethiopia is a patriarchal society that believes women are inferior to men (Haregewoin and Emebet, 2003). There is a belief that women are quiet, submissive, patient and tolerant of repetitive work and violence, for which culture is used as a justification (Hirut, 2004). The socialization process, which determines gender roles, is partly the reason for the oppression of women in the country. Ethiopian society is socialized as follows: girls are seen as inferior to boys. In addition, comparing the situation of women and men in Ethiopia, women are the most vulnerable and do not have access to formal work. According to Jones et al. (2010), "women typically have lower levels of education; less access, ownership and control of productive assets; less access to credit; and different social networks than men." As well as with extensive regional differences, a range of discriminatory, gendered practices overlook girls' and women's human capital development. For example, even though the claim that gender disparity in school enrolment has been highly reduced, studies indicate that literacy rates are still much different for men and women. 
Moreover, gendered-based violence, including rape and early marriage, are still extensive (Jones et al., 2010). Hence, all these gendered-based differences and discrimination make women less able to compete in the Ethiopian formal labor markets; Hallward-Driemeier and Gajigo (2010: 15) showed that, "in the Ethiopian labour market women are most insufficient among the professional/technical/management group followed by skilled labourers. (But) women are highly over-represented among artisans/crafts."

According to Haregewoin and Emebet (2002), women in Ethiopia are responsible for the larger share of informal economic operators. From the total population participating in the informal economy, around $60 \%$ of them are women. In the process of raising children, boys are expected to learn and become independent, major breadwinners and responsible in different activities, while girls are brought up to follow, be obedient and dependent, and specialize in indoor activities like cooking, washing clothes, fetching water, caring for children, and so on (Haregewoin and Emebet, 2003; Hirut, 2004). Similarly, a female informant in Arsi (2004) stated that a man is a big person who has higher social position and knowledge who can govern others and think in wider perspectives, while a woman is a person who can serve a man, who is like the husband's object transferred through marriage, and who should do anything he requests her to do (Hirut, 2004). These socially induced differences between males and females result in prejudiced rewards, statuses, opportunities and roles, as shall be discussed below. Low educational level is one of the causes and consequences of females' low socio-economic status. In spite of the fact that significant progress has been realized in girls' education during the last decade, a gender gap is still observed.

According to the Ministry of Education, the female enrolment rate in primary education has increased from $41 \%$ in 1999 and 2000 to $54 \%$ in 2002 and 2003; the respective figures for males are $61 \%$ and $75 \%$. This clearly shows that women are less empowered than men regarding education. The Gender Parity Index (GPI), the ratio of female-to-male enrolment, is now considered. Between the years 1999 and 2003, the GPI was found to be 0.7 , indicating that there were only seven girls enrolled at primary schools for every 10 boys (Federal Civil Service Commission, 2005). Similarly, the findings of the Central Statistics Authority (CSA) show that Ethiopian boys have more access to education than Ethiopian girls. As the greatest difference can be found in secondary education and adult literacy, action must be taken in order to eliminate the gender gap in these areas. According to UNESCO (2012), for every 100 boys enrolled in secondary education, there are approximately only 77 girls.

While enrolment in all secondary schools (Grades 9-12) has grown by more than $17.8 \%$ per year, reaching almost 1.5 million students in 2007 and 2008, in the first cycle, the rate for boys continued to dominate the rate of girls. It has been noted that the total number of students enrolled in Grades 11 and 12 (preparatory grades) in 2007 and 2008 was 193,444, 
out of which 32.5\% were girls (Educational Statistic Annual Abstract, 2007, 2008 ). When compared to that of 2003 and 2004, the enrolment at these grade levels showed an average annual increase of 19.6\% (Educational Statistic Annual Abstract, 2007, 2008). The total number of students enrolled in Grades 11 and 12 (preparatory grades) in 2008 and 2009 was 205,260 , out of which $27.6 \%$ were girls. However, in both cycles, the average annual growth rate was higher for girls than boys (Educational Statistic Annual Abstract, 2007, 2008). It has been noted that the total number of students enrolled in Grades 11 and 12 (preparatory grades) in 2010 and 2011 was 288,216, out of which 41.1\% were girls (Educational Statistic Annual Abstract, 2010, 2011 ). When compared to 2006 and 2007, the enrolment at this grade level showed an average annual growth of $13.2 \%$ (Educational Statistic Annual Abstract, 2010, 2011). In 2010 and 2011, the general enrolment rate for the preparatory program was $9.4 \%$ and $6.7 \%$ for boys and girls, respectively (Educational Statistic Annual Abstract, 2010, 2011). Overall, the secondary enrolment rate has increased, but the rate for boys is still greater than that for girls.

There has been a stable improvement in the participation of girls at primary school level, as expressed by the GPI. The GPI improved from 0.87 during 2004 and 2005 to 0.93 during 2009 and 2010. Likewise, for the same years under consideration, the GPI increased in the first years of secondary-level school (Grades 9 and 10) to 0.80 from 0.57. Gender parity in primary education is the highest in Addis Ababa, Amhara and Tigray and the lowest in Benshangul-Gumuz, Somali and Harari. Gender disparities increase as children pass upward from one level of the school system to the next. Women still constitute a small proportion of students at higher education institutions (29\% in higher education enrolment were female in 2007 and 2008; DHS, 2005, and preliminary report Central Statistical Agency, DHS, 2011).

In Ethiopia, women account for less than half (43\%) of the total employees in the country (CSA, 2004). Considering the percentage of female employees from the total number of employees by employment type, the highest was in domestic activities (78\%), followed by unpaid activities (59.3\%). In other types of formal employment (e.g., government, nongovernmental organizations (NGOs) and private organizations), the percentage of female workers is less than 35. Moreover, the survey showed overrepresentation of female workers in the informal sector. About $58 \%$ of working women work in the informal sector, whereas the percentage of working men in the informal sector was $37.7 \%$. Women make up $25 \%$ and $18 \%$ of the administrative and professional or scientific job categories, respectively, indicating that upper- and middle-level positions are dominated extensively by men (Federal Civil Service Commission, 2005).

Kabeer (2001) defines empowerment as "the expansion in people's ability to make strategic life choices in a circumstance where this ability was previously denied to them." This definition fits well within the referral to empowerment as "the expansion of freedom of choice and action to shape one's life" in the World Bank's Empowerment Sourcebook. It is 
believed to be multidimensional, existing in the economic, sociocultural, familial and interpersonal, legal, political and psychological realms (Malhotra et al., 2002). Extensive research has studied the association between women's empowerment and their maternal, child and reproductive health.

Some scholars recommend that women's empowerment increases with high educational and employment status and thus influences the number of children born (Kabeer, 1999; Upadhyay, 2009; Woldemicael, 2009). In most sub-Saharan African countries, the prevalence of contraceptive use is low and unwanted pregnancies are common (Upadhyay, 2009).

Education has been found to be correlated with the usage of maternal care services (Matthews, 2001 ). Bloom (2001) has found that female autonomy is a major determinant of maternal health care utilization in Uttar Pradesh, India. Maternal education also has been shown repeatedly to be positively associated with the utilization of maternity care services (Addai, 2000; Celik and Hotchkiss, 2000).

There is strong evidence that growing up in poverty is harmful for children (Ziol-Guest and Kalil, 2010 ). On the other hand, there is not much evidence that, above a very low threshold, additional income benefits children. Therefore, maternal employment could benefit children if it allows families to rise out of poverty. The socio-economic status of women is positively associated with maternal and child health (Girma and Genebo, 2002).

In Ethiopia, women's involvement in their own matters to take advantage of social, economic and political areas is inadequate. Bogalech and Mengistu (2007) found that social, traditional and economic values limit the rights of women and their chances to direct their own lives or participate in and contribute to community and national development.

Gender disparities exist in the division of labor, access to resources, dissemination of income and decision making. In Ethiopia, women are primarily responsible for food production and other household-level activities. Even though there has been an improvement, parity has not been attained yet. Rights to land, credit and other productive resources are difficult for women to attain. Due to women's disadvantaged position in society and as a commitment to gender equality, the Federal Democratic Republic of Ethiopia (FDRE) issued the national Ethiopian Policy on Women in 1993 and granted equal rights to women in its Constitution. In addition, recently, family law was introduced focusing on the improvement of women, positive action and provision for higher education, employment and promotion in the workplace (FDRE, 1993).

Ethiopia is also one of the countries that embraced the principles of the MDGs at the millennium declaration, where 147 heads of state and government and 191 nations became 
signatories of their adoption and implementation. A national action plan for gender equality is also underway to make the gender-specific goals of the MDGs a reality in Ethiopia.

The 2011 Ethiopia Demographic and Health Survey (EDHS) collected data related to women's empowerment and health outcomes, which makes available an excellent opportunity to study this relationship from the Ethiopian perspective. The numerous dimensions of empowerment- economic, sociocultural, familial and interpersonal, legal, political and psychological-may each influence the health outcomes of women. In classic demographic transition theory, the phenomena of lower mortality and fertility are very much interlinked, with lower mortality yielding subsequent lower fertility (Casterline, 2010). Although to address high fertility and a high unmet need for family planning, the country's contraceptive prevalence rate for married women is insufficient.

Kirdar et al. (2011) estimated the effect of compulsory schooling laws on teenage marriage and births in Turkey and showed that greater education allows marriage to be delayed. When women get married at an early age, they can produce more children than those who delay marriage. As well, there are consequences on the drop-out rate of girls from school. This study will explore the association between major dimensions of women's empowerment and maternal, child and reproductive health within married couples in Ethiopia.

\section{Methods}

\section{Data}

In order to clearly show gender inequality and women's empowerment in the country, bivariate, Cramer-V, chi-square and logistic regression techniques were used based on the variables supplied in both EDHSs 2005 and 2011. EDHS 2005 contained a total number of 14,070 eligible women, with a study sample of 8914 married women. According to EDHS 2011, there were 16,515 eligible women and the sample studied contained 9594 married women.

\section{Methods}

Bivariate, Cramer-V, chi-square and logistics regression models were used to demonstrate whether there is a significant difference between men and women with respect to selected socio-economic and demographic variables. Multivariate methods were used to determine the relative importance of identified explanatory variables in affecting major indicators for the gender gap, such as education and employment taken as dependent variables. The main explanatory variables include household characteristics and individual characteristics. Household characteristics take into account variables such as place of residence, region and wealth quintile, while individual characteristics include age, marital status and religion. Binary logistic regression models were applied for the multivariate analysis. Logistic regression models I, II, III and IV consider the association between a binary dependent variable and a set of independent variables. 


\section{Analyses}

There were four models applied, the dependent variables being educational attainment (illiterate $=0$; primary education and above $=1$ ) and work status $(\mathrm{No}=0 ; \mathrm{Yes}=1)$.

Model (I) assesses the effect of demographic and socio-economic variables on women's use of antenatal care.

Model (II) measures the impact of demographic and socio-economic variables on the place of most recent child birth.

Model (III) evaluates the effect of demographic and socio-economic variables on women's postnatal care.

Model (IV) assesses the effect of demographic and socio-economic variables on women's child immunization.

\section{Results}

\section{Maternal and child health utilizations with women's educational status}

The results show that 35 out of 100 women with some education use antenatal care, compared with 26 out of 100 women with no education. Similarly, 27 out of 100 women with some education are considerably more likely to have received postnatal care than seven out of 100 women with no education. Likewise, 22 out of 100 women with some education are significantly more likely to have delivered a baby at a health institute (clinic or hospital) than women with no education (seven out of 100 women).

However, 14 out of 100 women with some education are less likely to immunize their child for polio than those women with no education (28 out of 100) (Table 1). Thus, the educational status of women has a moderately positive associate with women and antenatal and postnatal care use (Figure 1).

\section{Maternal and child health utilizations with women's employment status}

Moreover, about 33 out of 100 women not working use antenatal care, compared with about 31 out of 100 currently working women. Likewise, about 15 out of 100 currently working women will have a baby delivered at a health institute (clinic or hospital), compared with about 16 out of 100 of those women not working. Similarly, 70 out of 100 women not working are less likely to have used child immunization as compared to nearly 79.5 out of 100 currently working women (Table 2). On the other hand, about 18 out of 100 currently working women are more likely to have received postnatal care than those women not working, which is about 13 out of 100 . Therefore, from the dependent variable, only postnatal care use and child immunization are significant with women's working status. 
Table I. Percentage distribution of maternal and child health utilizations with women educational status (DHS, 20II).

\begin{tabular}{|c|c|c|}
\hline Maternal and child health utilization & Women's education (if any) & No education \\
\hline \multicolumn{3}{|l|}{ Antenatal care use } \\
\hline Yes & 35.2 & 25.8 \\
\hline No & 64.8 & 74.2 \\
\hline \multicolumn{3}{|c|}{ Cramer's $V=($ Sig $=0.000$, Value $=0.224)$} \\
\hline \multicolumn{3}{|c|}{$X^{2}=69.10$} \\
\hline \multicolumn{3}{|l|}{ Postnatal care use } \\
\hline Yes & 27.1 & 7.1 \\
\hline No & 72.9 & 92.9 \\
\hline \multicolumn{3}{|c|}{ Cramer's $V=($ Sig $=0.000$, Value $=0.274)$} \\
\hline \multicolumn{3}{|c|}{$X^{2}=581.52$} \\
\hline \multicolumn{3}{|l|}{ Place of most recent child birth } \\
\hline Health facilities (clinic and hospital ) & 22 & 6.9 \\
\hline Home & 78 & 93.1 \\
\hline \multicolumn{3}{|c|}{ Cramer's $V=($ Sig $=0.000$, Value $=-0.2 \mid 2)$} \\
\hline \multicolumn{3}{|c|}{$X^{2}=164.77$} \\
\hline \multicolumn{3}{|l|}{ Child immunization use (polio) } \\
\hline Yes & 14.2 & 28.4 \\
\hline No & 85.8 & 71.6 \\
\hline \multicolumn{3}{|c|}{ Cramer's $V=($ Sig $=0.000$, Value $=-0.173)$} \\
\hline$X^{2}=168.57$ & & \\
\hline
\end{tabular}

Source: Ethiopia Demographic Health Survey 20II. Cramer's V value shows level of significance.

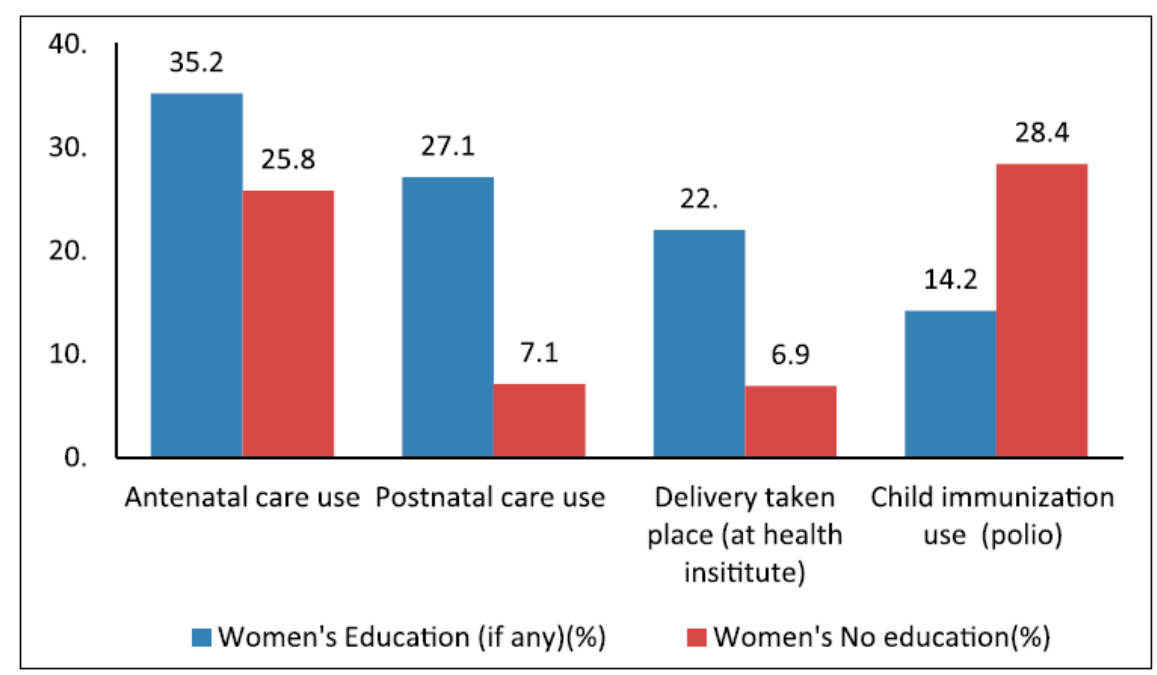

Figure I. Percentage distribution of maternal and child health utilizations with women educational status (DHS, 20II).

Source: Ethiopia Demographic Health Survey 20II.

Women's postnatal care use has a very weak positive relationship with work status. However, child immunization of polio use is weak positively associated with work status (Figure 2). 
Table 2. Percentage distribution of maternal and child health utilizations with women's employment status (DHS, 20II).

\begin{tabular}{|c|c|c|}
\hline Maternal and child health utilization & Women currently working & Not working \\
\hline \multicolumn{3}{|l|}{ Antennal care use } \\
\hline Yes & 30.7 & 33 \\
\hline No & 69.3 & 67 \\
\hline \multicolumn{3}{|c|}{ Cramer's $V=($ Sig $=0.141$, Value $=0.018)$} \\
\hline \multicolumn{3}{|c|}{$X^{2}=2.17$} \\
\hline \multicolumn{3}{|l|}{ Postnatal care use } \\
\hline Yes & 17.6 & 13 \\
\hline No & 82.4 & 86.8 \\
\hline \multicolumn{3}{|c|}{ Cramer's V $($ Sig $=0.000$, Value $=0.060)$} \\
\hline \multicolumn{3}{|c|}{$X^{2}=23.40$} \\
\hline \multicolumn{3}{|l|}{ Place of child birth } \\
\hline Health facilities (clinic and hospital ) & 14.8 & 15.5 \\
\hline Home & 85.2 & 84.5 \\
\hline \multicolumn{3}{|c|}{ Cramer's $V=($ Sig $=0.622$, Value $=0.008)$} \\
\hline \multicolumn{3}{|c|}{$X^{2}=0.244$} \\
\hline \multicolumn{3}{|l|}{ Child immunization use (polio) } \\
\hline Yes & 79.8 & 70.5 \\
\hline No & 20.2 & 29.5 \\
\hline \multicolumn{3}{|l|}{ Cramer's V $($ Sig $=0.000$, Value $=0.1)$} \\
\hline$X^{2}=23.62$ & & \\
\hline
\end{tabular}

Source: Ethiopia Demographic Health Survey 20II. Cramer's V value shows level of significance.

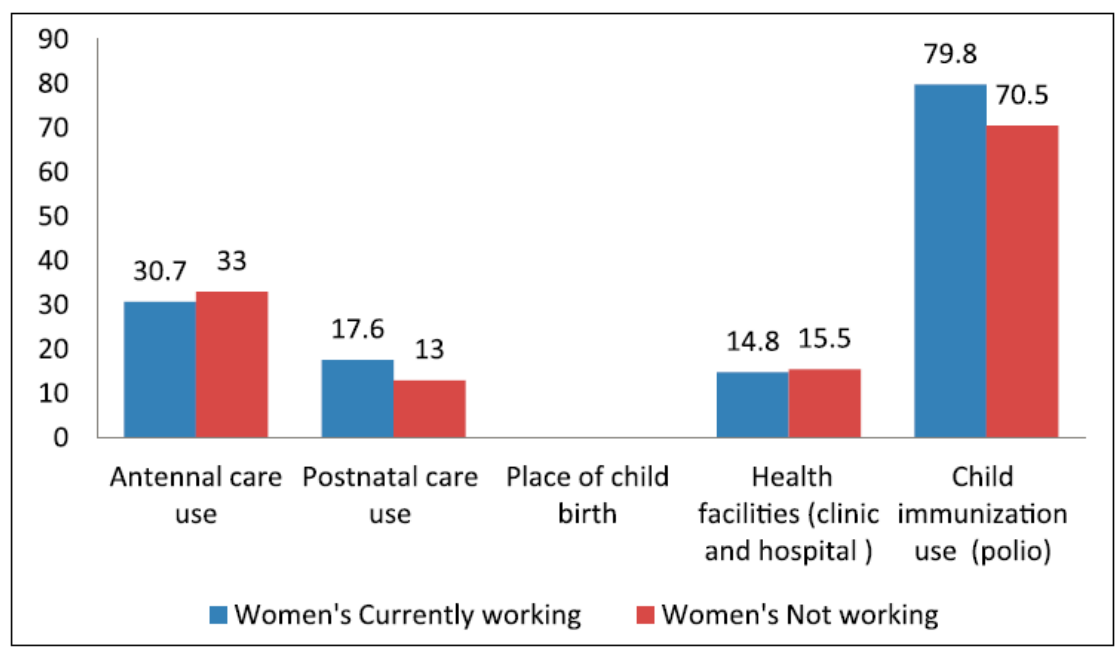

Figure 2. Percentage distribution of maternal and child health utilizations with women's employment status (DHS, 20II).

Source: Ethiopia Demographics Health Survey 20II. 


\section{Visited health facilities during the last 12 months and visited by family planning worker}

Next an example of 39 out of 100 women with some education visited health facilities, compared with about 31 out of 100 women with no education (Table 3). Likewise, about 17 out of 100 women with some education will be visited by family planning workers, compared with about 16 out of 100 of women with no education (Figure 3 ). Therefore, the educational status of women is very weakly positively associated with women visiting health facilities.

Table 3. Percentage distributions of visited health facilities during the last 12 months and visited by family planning worker with women's educational status (DHS, 20I I).

\begin{tabular}{lll}
\hline Dependent variables & Women with education (if any) & No education \\
\hline $\begin{array}{l}\text { Visited by family planning worker last I2 months } \\
\text { Yes }\end{array}$ & 16.6 & 16 \\
$\quad$ No & 83.4 & 84 \\
Cramer's $V=($ Sig $=0.348$, Value $=0.007)$ & & \\
$X^{2}=\mathbf{0 . 8 8}$ & & 31 \\
Visited health facilities worker & 39.1 & 69 \\
$\quad$ Yes & 60.9 & \\
No & & \\
Cramer's $V=($ Sig $=0.000$, Value $=0.085)$ & & \\
$X^{2}=118.13$ &
\end{tabular}

Source: Ethiopia Demographic Health Survey 20I I. Cramer's V value shows level of significance.

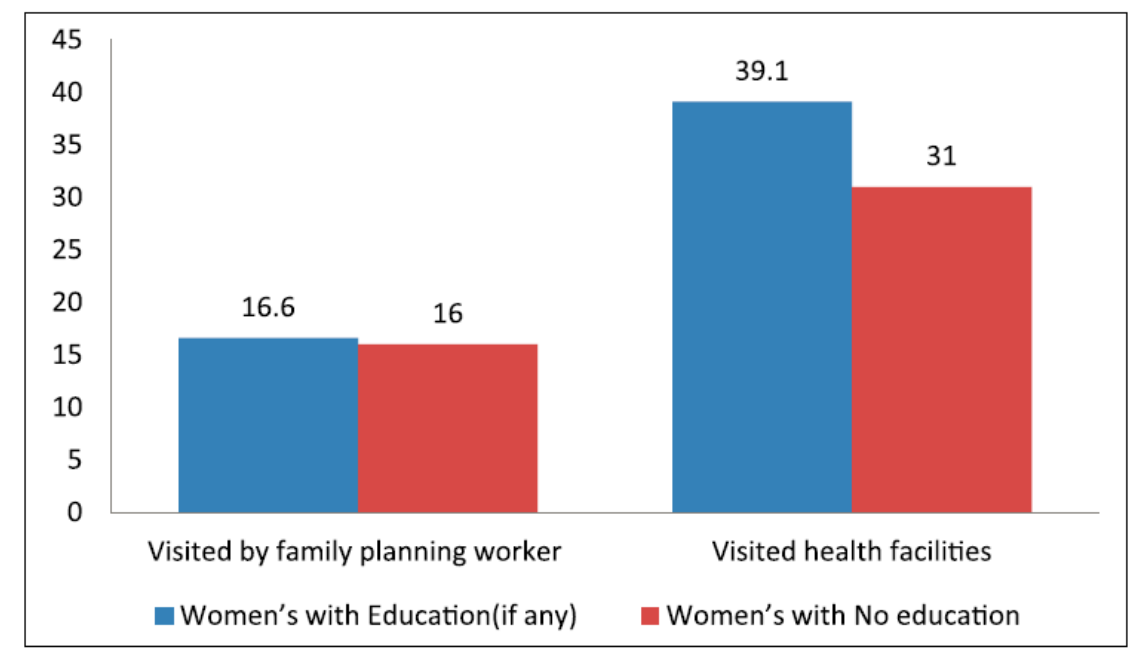

Figure 3. Percentage distributions of women who visited health facilities during the last 12 months and those that were visited by family planning workers with women's educational status.

Source: Ethiopia Demographic Health Survey 201 I. 


\section{Odds ratios of having visited health facilities during the last 12 months and being visited by a family planning worker}

The highest odds ratio of women's age groups versus visited health facilities in the last 12 months was the age group 20-24, which was 1.428. This indicated that women of the age group 20-24 were 1.428 times more likely to visit health facilities in the last 12 months than those of women of the age group 15-19. The highest odds ratio of a woman's age at fist cohabitation versus visiting health facilities was the age group 30-39, which was 1.52 (Table 4). This showed that women aged 30-39 at first cohabitation were 1.52 times more likely to visit health facilities in the last 12 months than those women of the age group 15-19. On the other hand, regarding the type of place of residence, women residing in rural areas were 0.395 times less likely to have visited health facilities in the last 12 months than women residing in urban areas. Moreover, currently working women were 1.241 times more likely to visit health facilities than those women who did not work. Similarly, women of the primary, secondary and higher education levels versus visiting health facilities were 1.558, 2.05 and 3.661 times, respectively, more likely to have visited health facilities in the last 12 months than women with no education. In addition, the highest odds ratio of a woman's wealth index versus visiting health facilities was the richest wealth quintile, which was about 3.3. This indicated that the richest women were 3.3 times more likely to visit health facilities than the poorest women. Finally, the age of the respondent, age at first cohabitation and socioeconomic variables were positively associated with having visited health facilities in the last 12 months. 
Table 4. Odds ratios of visited health facilities visited during the last 12 months and visited by family planning worker (DHS, 20II).

\begin{tabular}{|c|c|c|}
\hline Predictor variables & $\begin{array}{l}\text { Visited health } \\
\text { facilities } \operatorname{Exp}(B)\end{array}$ & $\begin{array}{l}\text { Visited by family planning } \\
\text { worker } \operatorname{Exp}(B)\end{array}$ \\
\hline \multicolumn{3}{|l|}{ Demographic variables } \\
\hline $\begin{array}{l}\text { Age of the respondent } \\
15-19 R C\end{array}$ & *** & *⿰冫⿰亅⿱丿丶丶 \\
\hline $20-24$ & 1.428 & 1.43 \\
\hline $25-29$ & 1.386 & 1.827 \\
\hline $30-34$ & I.34| & 2.222 \\
\hline $35-39$ & 1.425 & 2.409 \\
\hline $40-44$ & 1.038 & 2.266 \\
\hline $45-49$ & 0.898 & 1.677 \\
\hline \multicolumn{3}{|l|}{$10-19 R C$} \\
\hline $20-29$ & 1.415 & 0.973 \\
\hline $30-39$ & 1.52 & 1.595 \\
\hline 40 to last & 0.962 & 1.33 \\
\hline \multicolumn{2}{|l|}{ Urban RC } & $* *$ \\
\hline Rural & 0.395 & 1.037 \\
\hline \multicolumn{3}{|l|}{ Region } \\
\hline \multicolumn{3}{|l|}{ Tigray ${ }^{R C}$} \\
\hline Afar & 0.227 & 0.165 \\
\hline Amhara & 0.333 & 0.611 \\
\hline Oromiya & 0.383 & 0.357 \\
\hline Somali & 0.157 & 0.168 \\
\hline Ben- Gumz & 0.319 & 0.384 \\
\hline SNNP region & 0.331 & 0.404 \\
\hline Gambela & 0.538 & 0.191 \\
\hline Harar & 0.443 & 0.407 \\
\hline Addis Ababa & 1.02 & 0.485 \\
\hline Dire Dawa & 0.688 & 0.783 \\
\hline \multicolumn{3}{|c|}{ Worked for the last 12 month } \\
\hline Not workingRC & ** & ** \\
\hline Currently working & $1.24 \mid$ & 1.131 \\
\hline \multicolumn{3}{|l|}{ Educational level } \\
\hline No education $\mathrm{RC}$ & $* *$ & ** \\
\hline Primary & 1.558 & 1.163 \\
\hline Secondary & 2.05 & I.III \\
\hline Higher & 3.661 & 1.281 \\
\hline \multicolumn{3}{|l|}{ Wealth index } \\
\hline Poorest ${ }^{R C}$ & $* *$ & ** \\
\hline Poorer & 1.315 & 1.617 \\
\hline Middle & 1.435 & 1.367 \\
\hline Richer & 1.758 & 1.856 \\
\hline Richest & 3.277 & 1.586 \\
\hline
\end{tabular}

Source: Ethiopia Demographic and Health Survey 20II. Adjusted odds ratios for visited health facilities last 12 months and

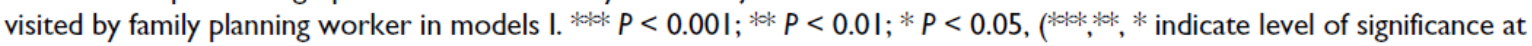
specified level). RC: reference category; SNNP region: Southern Nations, Nationalities and Peoples' region. 
The highest odds ratio of a woman's age at first cohabitation versus being visited by a family planning worker was the age group 30-39, which was about 1.6 (Table 4). This showed that women first cohabiting at age 30-39 were 1.6 times more likely to be visited by a family planning worker than women of the age group 15-19. On the other hand, regarding the types of place of residence, women residing in rural areas were about 1.04 times more likely to be visited by a family planning worker than women who were residing in urban areas. Furthermore, currently working women were 1.131 times more likely to be visited by a family planning worker than those women who did not work. Likewise, women with primary, secondary and higher education versus visiting health facilities were $1.163,1.111$ and 1.281 times, respectively, more likely to be visited by a family planning worker than those women with no education. In addition, the highest odds ratio of women's wealth quintile versus being visited by a family planning worker was the richer wealth quintile, which was about 1.86. This indicated that richer women were 1.86 times more likely to be visited by a family planning worker than those women in the poorest wealth quintile.

\section{Odds ratios of the relationship between demographic and socio-economic variables with maternal and child health care}

Model (I) antenatal care. The respondent age groups 20-24, 25-29, 30-34 and 35-39 corresponded to odds ratios for use of antenatal care, respectively, at 2.15, 2.09, 1.82 and 1.27. This indicated that women in the age groups 20-24, 25-29, 30-34 and 35-39 were 2.15, 2.09, 1.82 and 1.27 times more likely to use antenatal care than those aged 15-19, respectively. Women in the age groups 40-44 and 45-49 were 0.57 and 0.19 times, respectively, less likely to use antenatal care than those age 15-19 (Table 5). Women residing in rural areas were 0.88 times less likely to use antenatal care than women living in urban areas. The odds ratio of currently working women versus use of ante-natal care was 0.45 ; these show currently working women were 0.45 times less likely to use ante-natal care than women who don't work. Women with secondary education had the highest odds ratio of antenatal care, which was about 1.45 . This indicated that women with secondary education were 1.72 times more likely to use antenatal care than women with no education. The strongest predictor of women's use of antenatal care was the richer wealth quintile, recording an odds ratio of $\mathbf{1 . 8 2}$. This showed that women in the richest wealth quintile were 1.82 times more likely use antenatal care than those in the poorest wealth index. Therefore, demographic predictors, age of the respondent and region, as well as socio-economic variables, having worked for the last 12 months, educational level and wealth index were significantly associated with women's use of antenatal care. The independent variables of age of the respondent, educational level and wealth index of women were positively associated with women's use of antenatal care. Type of place of residence, region and having worked for the last 12 months were negatively associated with the use of ante-natal care. 
Table 5. Odds ratio of maternal and child health care utilization in currently married women in Ethiopia (DHS, 20II).

\begin{tabular}{|c|c|c|}
\hline Indicators & $\begin{array}{l}\text { Model I antenatal } \\
\text { care (yes) Ex(B) }\end{array}$ & $\begin{array}{l}\text { Model II place of most recent } \\
\text { child birth (at home) } \operatorname{Ex}(\mathrm{B})\end{array}$ \\
\hline \multicolumn{3}{|l|}{ Demographic indicators } \\
\hline Age of the respondent $(15-19)^{R C}$ & $* *$ & ** \\
\hline $20-24$ & 2.154 & 0.557 \\
\hline $25-29$ & 2.085 & 0.692 \\
\hline $30-34$ & 1.817 & 0.793 \\
\hline $35-39$ & 1.273 & 1.109 \\
\hline $40-44$ & 0.572 & 2.406 \\
\hline $45-49$ & 0.19 & $1.97 \mid$ \\
\hline $\begin{array}{l}\text { Type of place of residence (urbar } \\
\text { Urban }\end{array}$ & & 冰 \\
\hline Rural & 0.881 & 25.359 \\
\hline Region(Tigray) ${ }^{\mathrm{RC}}$ & & **⿰冫⿰亅⿱丿丶丶 \\
\hline Affar & 0.344 & 1.655 \\
\hline Amhara & 0.326 & 1.578 \\
\hline Oromiya & 0.618 & 1.721 \\
\hline Somali & 0.294 & 2.312 \\
\hline Benishangul-Gumuz & 0.526 & 1.739 \\
\hline SNNP region & 0.587 & 3.09 \\
\hline Gambela & 0.491 & 0.49 \\
\hline Harari & 0.668 & 0.383 \\
\hline Addis Ababa & 0.599 & 0.032 \\
\hline Dire Dawa & 0.744 & 0.329 \\
\hline \multicolumn{3}{|l|}{ Socio-economic indicators } \\
\hline Currently working (No) RC & & **⿰冫⿰亅⿱丿丶丶 \\
\hline Currently working & 0.45 & 5.71 \\
\hline Educational level (none) RC & $* *$ & \\
\hline Primary & 1.566 & 0.411 \\
\hline Secondary & 1.723 & 0.077 \\
\hline Higher & $1.37 \mid$ & 0.049 \\
\hline Wealth quintile(poorest) ${ }^{R C}$ & $* *$ & \\
\hline Poorer & 1.465 & 0.538 \\
\hline Middle & 1.575 & 0.671 \\
\hline Richer & 1.818 & 0.385 \\
\hline Richest & 1.724 & 0.032 \\
\hline
\end{tabular}

Source: Ethiopia Demographic and Health Survey 20II. Adjusted odds ratios for antenatal care use and place of child birth in currently married women in model II.

$* * \cdots * 0<0.00$ I; $* * P<0.01 ; * P<0.05$, (******** indicate level of significance at specified level). RC: reference category; SNNP region: Southern Nations, Nationalities and Peoples' region.

Model (II) most recent childbirth. From demographic variables, place of residence and region, as well as all socio-economic variables, having worked for the last 12 months, educational level and wealth quintile of women, were statistically significant for place of birth of the most recent child. The odds ratio of women residing in rural areas with the place 
of birth of the most recent child was about 25.36. This indicated that women living in rural areas were 25.36 times more likely to give birth at home (without the assistance of a health institute such as a clinic or hospital) than women living in urban areas. Likewise, the highest odds ratio of women residing in a Southern Nations, Nationalities and Peoples' Region (SNNP region) with the place of birth of the most recent child was 3.09. This showed that women from a SNNP region were 3.09 times more likely to give birth at home than women in the Tigray region. Women from Addis Ababa were 0.032 times less likely give birth at home than women in the Tigray region. On the other hand, the odds ratios of women's primary, secondary and the highest educational level versus the place of child birth were 0.411 , 0.077 and 0.049 , respectively. This shows that women with primary, secondary and tertiary educational levels were $0.411,0.077$ and 0.049 times less likely to give birth at home than women with no education, respectively. Moreover, women within the richest wealth index were 0.032 times less likely to give birth without the assistance of a health institute, such as a clinic or hospital, than women within the poorest wealth quintile.

Model (III) postnatal care. From demographic variables, type of place of residence and region, as well as all socio-economic variables, having worked for the last 12 months, educational level and wealth index of women, were statistically significant for postnatal care. The odds ratio of women living in rural areas with postnatal care was about 0.09. This indicates that women living in rural areas were 0.09 times less likely to use postnatal care than women living in urban areas. Likewise, the highest odds ratio of women residing in the Addis Ababa region versus postnatal care was 6.20. This shows that women from the Addis Ababa region were 6.20 times more likely to use postnatal care than women in the Tigray region. Women from the SNNP region were 0.36 times less likely use postnatal care than women in the Tigray region. On the other hand, the odds ratios of women's primary, secondary and highest tertiary-level education versus postnatal care were 3.09, 18.25 and 28.88 , respectively. This shows that women with primary, secondary and higher educational levels were $3.09,18.25$ and 28.88 times more likely to use postnatal care than women with no education, respectively. Moreover, women within the richest wealth index were 14.08 times more likely use postnatal care than women within the poorest wealth quintile.

Model (IV) immunization. The highest odds ratio of respondent age group versus women's use of immunization for their child was the age group 30-34, which was about 11.52. This indicates that women in the age group 30-34 were 11.52 times more likely to use immunization than those aged $15-19$. Women residing in rural areas were 3.22 times more likely to use immunization for their child than women living in urban areas.

The odds ratio of currently working women versus use of immunization was 0.92; this shows that currently working women were 0.92 times less likely to use immunization than women who do not work. The respondent primary, secondary and higher education levels had corresponding odds ratios for use of immunization at $0.511,0.22$ and 0.20 , respectively. This indicates that women with primary, secondary and higher educational levels were 
$0.511,0.22$ and 0.20 times, respectively, less likely to use immunization than women with no education. The strongest predictor of women's use of immunization was the poorer wealth quintile, recording an odds ratio 1.09. This indicated that women in the poorer wealth quintile were 1.09 times more likely to use immunization than those of the wealthier quintiles. The independent variables of age, place of residence and region were positively associated with their use of immunization.

\section{Discussion}

The data show that there are fewer women with secondary or higher education compared with men; this is even more so among women with primary education. In both 2005 and 2011, it was mostly women who had no educational attainment. In 2011, 50.10\% of women had no education compared with $31.50 \%$ of men. Concerning literacy, the study's findings have shown that women are more likely to be illiterate than men. This could be driven by the fact that girls (or women) are often married off at very young ages, which serves as a barrier to their education and literacy levels (Erulkar, 2013). These results clearly show the gender gap in education in the country. Education has already been related to women's empowerment; hence, it is important to improve women's education as a way of empowering them and giving them autonomy to have the power to make crucial decisions about their lives. Results from a study conducted from 2009 to 2010 in Ethiopia pointed out that education is among the key factors in women's empowerment-where it was correlated with knowledge of marriage as well as the autonomy (or power) to engage in discussions about fertility and reproductive health issues in young girls (Erulkar, 2013). The logistics regression analysis showed that primary and secondary education is associated with age, wealth quintile, region and religion. Employment of women was significantly less than that of men in both 2005 and 2011. Women who reside in rural areas and those who are from the richest households (characterized by the richest wealth quintile) are more likely to have primary education and above as well as being more likely to be working. In rural areas, where education is not encouraged among girls and where there are strict gender roles (i.e., a woman only exists for purposes of marriage and reproduction), tradition and culture do not support women to go out and work or earn a living. As a result of the negative effect of culture and tradition, husbands do not permit women to go out and work; they would be considered as turning aside from the norm. Besides this cultural obstruction, there seems to be further economic restriction among the poor, uneducated women where these restrictions make it difficult for them to start even small-scale income-producing work. In many cases, having many children, coupled with the heavy daily workload at home to maintain the family, does not leave much time to venture outside to work. The cultural barriers preventing women from working to earn a living were strongly stated in the Gambella, Somali and SNNP regions.

The results indicated that men have shown greater desire for having more children than women in 2005. In 2011, this trend changed, where women and men had almost the same desire for having more children, which was $72.00 \%$ and $71.38 \%$, respectively. The demand 
for limiting family size was higher for women than men in 2005. Conversely, in 2011, the demand for limiting family size was higher for men than women. On the other hand, men are the principal if not the sole decision makers regarding controlling fertility of women in most of the societies, particularly in rural areas. A study on gender inequality and the empowerment of women in Ethiopia suggested that children are often held in high regard in the country, where they are seen as prized possessions who will grow up and benefit the parents financially (especially girls, who will be married off and thus bring wealth, through dowry, to the family; Ethiopian Society of Population Studies, 2008). It is this kind of thinking that serves as a barrier to women's empowerment-especially where young girls are regarded as having less value than boys. Culture and religion are often used interchangeably to promote or justify the worldviews of those who practice customs such as child marriages (Ethiopian Society of Population Studies, 2008).

Women who cohabited at younger ages were less likely to visit health facilities than older women, except women of age 40 and above. Likewise, women who got married at younger ages were less likely to be visited by a family planning worker than older women, except for the age group of 20-29. Women in the Addis Ababa region were about one time more likely to visit health facilities than women from the Tigray region. Women from Tigray were more likely to visit health facilities than the rest of regions, except Addis Ababa. On the other hand, women in the Dire Dawa region were extremely in need of being visited by a family planning worker and using antenatal care compared with other women in the Ethiopian region. The age of the respondent, age at first cohabitation and socio-economic variables were positively associated with having visited health facilities in the last 12 months and being visited by a family planning worker. Women's decision making alone was significantly important for maternal and child health care. Women who gave birth at home were negatively associated with educational level and wealth indices. SNNP women who gave birth at poor health facilities meant that more of them had given birth at home compared with other regions. Female empowerment, through education, economic independence, respect for women's rights and political representation, was also mentioned as the second-most possible solution. Thus, empowered women are less likely to tolerate their husbands' unmannerly acts (Yigzaw et al., 2004). 
Table 6. Odds ratios of maternal and child health care utilization in currently married women in Ethiopia (DHS, 20II).

\begin{tabular}{|c|c|c|}
\hline Background characteristics & $\begin{array}{l}\text { III Postnatal care } \\
\text { (yes) Ex(B) }\end{array}$ & $\begin{array}{l}\text { IV Immunization } \\
\text { (polio = yes) } \operatorname{Ex}(B)\end{array}$ \\
\hline \multicolumn{3}{|l|}{ Demographic characteristics } \\
\hline Age of the respondent $(15-19)^{R C}$ & ** & *** \\
\hline $20-24$ & $\mathrm{I} .374$ & 6.899 \\
\hline $25-29$ & 1.256 & 11.434 \\
\hline $30-34$ & 1.077 & 11.516 \\
\hline $35-39$ & 0.946 & 9.306 \\
\hline $40-44$ & 0.609 & 6.679 \\
\hline $45-49$ & 0.566 & 2.697 \\
\hline $\begin{array}{l}\text { Type of place of residence (urban) } \\
\text { Urban }\end{array}$ & & 冰 \\
\hline Rural & 0.086 & 3.221 \\
\hline \multicolumn{3}{|l|}{ Region(Tigray) ${ }^{R C}$} \\
\hline Affar & 0.456 & 0.778 \\
\hline Amhara & 0.405 & 1.44 \\
\hline Oromiya & 0.412 & 1.148 \\
\hline Somali & 0.49 & 1.103 \\
\hline Benishangul-Gumuz & 0.591 & 1.445 \\
\hline SNNP region & 0.358 & $1.69 \mid$ \\
\hline Gambela & 1.079 & 1.673 \\
\hline Harari & 2.675 & 0.837 \\
\hline Addis Ababa & 6.197 & 0.172 \\
\hline Dire Dawa & 1.798 & 0.724 \\
\hline Socio-economic characteristics & ** & \\
\hline \multicolumn{3}{|l|}{ Currently working (No) ${ }^{\mathrm{RC}}$} \\
\hline Currently working & 1.563 & 0.924 \\
\hline Educational level (none) $)^{\mathrm{RC}}$ & $* *$ & \\
\hline Primary & 3.087 & 0.511 \\
\hline Secondary & 18.248 & 0.22 \\
\hline Higher & 28.883 & 0.196 \\
\hline Wealth quintile(poorest) ${ }^{\mathrm{RC}}$ & ** & \\
\hline Poorer & 1.116 & 1.086 \\
\hline Middle & I.I & 0.973 \\
\hline Richer & 2.372 & 0.915 \\
\hline Richest & 14.076 & 0.335 \\
\hline
\end{tabular}

Source: Ethiopia Demographic and Health Survey 20II. Adjusted odds ratios for postnatal care use and child immunization in currently married women in model III.

$* * * P<0.001$; ** $P<0.01$; $* P<0.05$ (******, * indicate level of significance at specified level).

RC: reference category; SNNP region: Southern Nations, Nationalities and Peoples' region.

The effect of socio-economic indicators differs for use of postnatal care and child immunization. This study shows that postnatal care is higher for women living in urban areas than for those women living in rural areas. On the other hand, child immunization is higher for women residing in rural than urban areas. Moreover, for working women, postnatal care use is higher than for women who do not work. Working women's child 
immunization use is lower than for women who do not work. Furthermore, women with higher education are more likely to use postnatal care than women with no education. Women with higher education are less likely to use child immunization services than women with no education. From these, we can conclude that predictor variables of age and educational level, working status and wealth index of women are positively associated with postnatal care use. In addition to this, child immunizations (polio) are positively associated with the age of the respondents and place of residence of women.

With respect to the effect of socio-economic factors on postnatal care use, the results appear to be consistent with most studies done elsewhere, which indicate that women with higher education are significantly more likely to use postnatal care than women with no education. Maternal education also has been shown repeatedly to be positively associated with the utilization of maternity care services (Addai, 2000). Educated mothers are more likely to seek health care services than less educated women (Bell et al., 2003; Celik and Hotchkiss, 2000 ). Women with low awareness, who are less empowered and with economic constraints during referrals were found to be the main reasons that most women gave birth at home in Kembatta-Tembaro, Ethiopia (Solomon et al., 2013 ). Cost is an important limiting factor for maternity service seeking in many rural areas. Where distance to the next level of care is a barrier, costs to cover transportation and lodging expenses become particularly important. A study finding in Nepal has found that maternal education and maternal occupation were significantly associated with the postnatal care attendance after controlling for community factors, ethnicity and religion (Khanal et al., 2014). Another study in Bangladesh confirmed that women's educational levels were positively associated with their use of postnatal care and can be explained by the notion that mothers with higher levels of education are more likely to be informed about health risks and demand and gain access to health care (Rahman et al., 2010 ). Similarly, mothers who are involved in paid employment are more likely to be economically independent and, as a result, they have access to services and utilize the services when they need or as suggested by their health workers (Chakraborty et al., 2002).

\section{Conclusion}

Decisions made jointly on how to spend the women's money, manage health care, purchase large household items and get around also have significant impacts on utilizing childbirth facilities. At the same time, decisions made jointly regarding respondents' own health have significantly greater influences on the use of postnatal care services. In addition, women who can make the final decision alone on their health care, large household purchases and mobility are more likely to use postnatal care than women who do not have a final say. On the other hand, women who can make final decisions alone on their earnings and large household purchases are more likely to use immunization services than women who do not have a final say. 
The common dimensions of married women's empowerment, namely education and employment status, are positively associated with the wealth index and age of respondent, region and religion. In addition, the study indicated that high gender disparity due to socio-economic indicators has been recorded in Ethiopia. We conclude that married women with primary educational attainment and above are less likely to get married at an early age than those who are uneducated. This does not eliminate the chances of being married at an early age (i.e., at ages less than 18 years), but it suggests that it limits and empowers girls to be aware of their rights. Thus, we recommend that women must be empowered in terms of decision-making power, purchasing power, increasing age at marriage and integrated into family planning programming in Ethiopia, and that these issues must be focused at the vulnerable group (which is young girls, those less than 18 and those aged 18-24). Those mothers who are highly educated or working in higher level positions must collaborate to promote an increase in the status of women. Health care service providers, policy makers, program managers and government and nongovernment organizations must work together to eliminate gender inequality and provide equal status to men and women; action is needed to increase the status of women in employment opportunities. There was a significant relationship between the status of women and a good quality of life, and this relationship appeared to differ by education and work status. Further in-depth, qualitative analysis is recommended. This study shows that the most significant factors influencing the use of antenatal and postnatal care services in Ethiopia are demographic and socio-economic in nature. However, this does not reduce the relevance of service-related factors, especially in rural areas. The demographic and socio-economic factors affecting women's health outcomes (antenatal and postnatal care use, place of childbirth and child immunization) identified in this study include age of the respondent, age of first cohabitation, place of residence, religion, education, work status and wealth quintile, which are similar to those documented in many settings throughout Africa and other developing countries. Formerly, education and wealth quintile were found to have an important impact on the use of antenatal and postnatal care; improving educational opportunity and the wealth quintile for women may have a large impact on improving antenatal and postnatal health care use. However, this is a long-term plan. As an alternative, in the short term, health programs need to focus on attracting women with little or no education. Secondly, that rural women were less likely to use the services means that maternal health care programs such as health extensions (only known in Ethiopia) should be extended and increased in rural areas along with culturally appropriate education promotions. Lastly, early marriage was found to have a negative impact on the use of antenatal care, postnatal care and child immunization, supporting an initiative to delay the age of marriage through economic incentives that keep girls in school and provide life-skills training. In a number of ways, the local parent-teacher association and Girls' Advisory Committee, working with local government officials, have to get involved with parents and religious elders, who have arranged early marriages of girls as young as 10, and convince them to increase female marriage age and keep the girls in school.

\section{http://repository.uwc.ac.za}




\section{Acknowledgements}

The authors would like to thank Jarita C Holbrook, California Institute of Technology, Honolulu, Hawaii for her incredible comments and suggestions.

\section{Declaration of Conflicting Interest}

The author(s) declared no potential conflicts of interest with respect to the research, authorship and/or publication of this article.

\section{Funding}

This research received no specific grant from any funding agency in the public, commercial or not-for-profit sectors. 


\section{References}

Addai I (2000) Determinants of use of maternal-child health services in rural Ghana. Journal of Biosocial Science 32(1): 1-15.

Agha S (2000) The determinants of infant mortality in Pakistan. Social Science and Medicine 51: 199-208. Bell J, Sian L. Curtis and Siliva A (2003) Trends in Delivery Care in Six Countries. DHS Analytical Studies No. 7. Calverton, MD: ORC Macro.

Bianchi SM (2000) Maternal employment and time with children: dramatic change or surprising continuity? Demography 37(4): 401-414.

Bloom SS, Wypij D and Gupta MD (2001) Dimensions of women's autonomy and the influence on maternal health care utilization in a north Indian city. Demography 38(1): $67-78$.

Bogalech A and Mengistu A (2007) Women's Empowerment in Ethiopia, New Solutions to Ancient Problems. Addis Ababa: Pathfinder International/Ethiopia.

Casterline J (2010) Wanted fertility, unwanted fertility, and fertility decline: a fresh assessment. In: annual meeting of the Population Association of America, Dallas, April.

Central Statistical Agency (2006) Ethiopia Demographic and Health Survey. ORG Measures and Evaluation, Maryland: Macro international; 2005.

Central Statistical Agency (2012) Ethiopia Demographic and Health Survey. ORG Measures and Evaluation, Maryland: Macro international; 2011.

Celik Y and Hotchkiss DR (2000) The socio-economic determinants of maternal health care utilization in Turkey. Social Science and Medicine 50(12): 1797-1806.

Chakraborty N, Islam MA, Chowdhury RI, et al. (2002) Utilization of postnatal care in Bangladesh: Evidence from a longitudinal study. Health and Social Care in Community 10: 492-502.

CSA (2004) Urban bi-annual employment unemployment survey. Addis Ababa.

Duncan GJ, Ziol-Guest KM and Kalil A (2010) Early-childhood poverty and adult attainment, behavior, and health. Child Development 81(1): 306-325.

Ethiopian Society of Population Studies (2008) Gender Inequality and Women's Empowerment: In-depth Analysis of the Ethiopian Demographic and Health Survey, 2005. Addis Ababa: Ethiopian Society of Population Studies.

Erulkar A (2013) Early marriage marital relations and intimate partner violence in Ethiopia. International Perspectives on Sexual and Reproductive Health 39(1): 6-13.

Federal Democratic Republic of Ethiopia (1993) The Transitional Government of Ethiopia. National Policy on Ethiopian Women, Addis Ababa.

Federal Civil Service Commission (2005) Survey on the status of men and women employees and strategies for gender equality. Main Report, Addis Ababa.

Girma W and Genebo T (2002). Determinants of nutritional status of women and children in Ethiopia. Ethiopia Health and Nutrition Research Institute, Addis Ababa, Ethiopia. ORC Macro Calverton, Maryland, USA. Hallward-Driemeier M and Gajigo O (2010) Where women work: Empowerment and occupational choice. Working Paper. 
Haregewoin C and Emebet M (2002) Country Gender Profile Ethiopia. Addis Ababa, Ethiopia: Sida, Swedish International Development Cooperation Agency.

Haregewoin C and Emebet M (2003). Towards gender equality in Ethiopia. A profile of gender relations. Swedish International Development Cooperation Agency.

Hirut T (2004). Violence against women in Ethiopia: A strong case of civil society concern. In: Chowdhury S, Wais A and Giorgis KW (eds) Civil Society in Ethiopia: Reflections on Realities and Perspectives of Hope. African - Asian Studies Promotion Association, Addis Ababa, /Ethiopia.

Jones N, Tafere Y and Woldehanna T (2010) Gendered risks, poverty and vulnerability in Ethiopia: To what extent is the Productive Safety Net Programme (PSNP) making a difference. London: Overseas Development Institute.

Kabeer N (2001) Reflections on the measurement of women's empowerment. In: discussing women's empowerment-theory and practice, Sida Studies No. 3. Novum Grafiska AB: Stockholm.

Kabeer N (1999) Resources, agency, achievements: Reflections on the measurement of women's empowerment. Development and Change 30(3): 435-464.

Khanal V, Adhikari M, Karkee R, et al. (2014) Factors associated with the utilisation of postnatal care services among the mothers of Nepal: Analysis of Nepal Demographic and Health Survey 2011. BMC Women's Health 14(1): 19.

Kirdar M, Tayfur M and Koç I (2011) The effect of compulsory schooling laws on teenage marriage and births in Turkey. IZA Discussion Paper $\mathrm{N}^{\circ} 5887$.

Malhotra A, Schuler SR and Boender C (2002) Measuring Women's Empowerment as a Variable in International Development. Washington, DC: The World Bank.

Matthews Z, Mahendra S, Kilaru A, et al. (2001) Antenatal care, care-seeking and morbidity in rural Karnataka, India: Results of a prospective study. Asia Pacific Population Journal 16(2): 11-28.

Ministry of Education (MoE) (2010a) Growth and transformation plan. Addis Ababa, Ethiopia: Ministry of Education. Available at: http://www.mofed.gov.et/English/Resources.

Ministry of Education (MoE) (2010b) Education Sector Development Program IV (ESDP IV), 2010/11 - 2014/15, Program Action Plan. Addis Ababa: Ministry of Education.

Ministry of Education (MoE) (2009) Education Statistics Annual Abstract 2000 E.C (2007-2008). Addis Ababa, Ethiopia: Education Sector Development Program Planning and Policy Analysis Department.

Rahman M, Haque S and Zahan S (2010) Factors affecting the utilization of postpartum care among young mothers in Bangladesh. Health and Social Care in the Community. Epub ahead of print 2010. DOI: 10.1111/j.1365-2524.2010.00953.x.

Shiferaw S, Spigt M, Godefrooij M, et al. (2013) Why do women prefer home births in Ethiopia? BMC Pregnancy and Childbirth 13(1): 5. DOI: 10.1186/1471-2393-13-5.

UNESCO (2012) Ethiopia EFA (Education for All) Profile. Dakar: UNESCO.

Upadhyay UD (2009) Women's empowerment and achievement of desired fertility in subSaharan Africa. Oakland, CA: Advancing New Standards in Reproductive Health 
(ANSIRH), Bixby Center for Global Reproductive Health, University of California, San Francisco.

Woldemicael G (2009) Women's autonomy and reproductive preferences in Eritrea. Journal of Biosocial Science 41(2): 161-181.

Yigzaw T, Yibrie A and Kebede Y (2004).Domestic violence around Gondar in Northwest Ethiopia. Ethiopian Journal of Health Development 2004; 18(3): 133-139.

\section{Author biographies}

Yishak Lailulo is a doctoral research fellow at the Department of Statistics and Population Studies, University of the Western Cape, South Africa.

A Sathiya Susuman is an associate professor at the Faculty of Natural Sciences, Department of Statistics and Population Studies, University of the Western Cape, South Africa. His research interests include technical demography, fertility, mortality, gender, reproductive health, vulnerable diseases, HIV/AIDS, health policy and public health. He has published several international accredited journal articles in BMC Reproductive Health, BMC Research Note, the International Journal of Equity in Health, the Journal of Public Health, SAHARA J: Journal of Social Aspects of HIV/AIDS Research Alliance, the Journal of Social Science Research, the Journal of Asian and African Studies, Plos One, Clinical Case Report, the Iranian Journal of Public Health and in other journals and edited volumes.

Renette Blignaut is a professor and deputy head of the Department of Statistics and Population Studies, University of the Western Cape, South Africa. Her special areas of research are biostatistics, science education and data mining. 